\title{
Design Discipline Construction Based on Subliminal Theory
}

\author{
Wu Ping \\ Product Design Department \\ Fashion and Art Design Institute \\ Donghua University \\ Shanghai, China \\ snilsong@163.com
}

\begin{abstract}
This paper tries to find the guiding ideology of discipline construction suitable for the design subject. By comparing creative design activity with subconscious activities, it revealed the similarity and the close relationship of the two types of activities. At the same time, it proposed the key role of subconscious activity in art design creation and the significance of the subliminal theory in guiding design discipline construction. Some suggestions for design discipline construction are put forward: 1.Attach importance to information input to enhance image memory and comprehension, and attach importance to the study of the form, quality and effective input of such information in order to improve the efficiency of information absorption efficiency; 2.pay attention to the characteristics of spiritual life when the subconscious mind or creative thinking is active, and carry out the research on the way of thinking training in design discipline; 3. Study the teaching environment of art design that can help improve creative thinking according to the mental life characteristics of subliminal activities. For the first time, this paper attempted to compare subconscious activity with creative design thinking through the theoretical knowledge and experiences of them, and found the correlation between them. What's more, it put forward some innovative suggestions as to art design discipline construction based on subliminal theories and the experiences of creative art design activities.
\end{abstract}

Keywords-subconscious; creativity; information input; design thinking; teaching environment;

\section{INTRODUCTION}

The theory of subconscious is mainly applied in the field of psychology and the development and the training of individuals and organizations. In the field of art and design, some people have actually done some creative work based on the remembered dreams. There are also some people who has tried to put themselves into a subconscious state and created. These personal practices show that the concept of subconscious has entered into the visual field of art design.

In recent years, according to the papers in the field of art design, subconscious is being valued in the art design education world.

\section{A. The evidence of subconscious mind}

The subconscious mind was put forward first by the psychologist Sigmund Freud in his theory "Psychoanalysis". It was discovered and proved by physician Mesmer with her hypnosis in Vienna, Austria to be relative to "consciousness", which is like conscious mind, and which can directly control people's behavior or language. When people's conscious minds are awake, they are guided and monitored by their conscious minds. [1]

\section{B. The concept of subconscious}

- Freud believed that the subconscious mind had to do with the human instinct. In his theory, he mentioned that people had a life instinct for fulfillment, enjoyment, and happiness, which was an intrinsic power of human beings, and which was opposite to rational. He called it the subconscious mind. Freud believed that this subconscious mind, though invisible, unconsciously controlled the language and the behavior of human beings.[2]

- George Frankel, a contemporary psychoanalyst with 40 years of clinical experience, believes that the subconscious mind is connected to people's memories. In his book "Exploring the subconscious", he says that the subconscious mind is the information deployment mechanism (responsible for the acceptance, transmission, storage, consolidation and conversion process of information) in the brain which processes "non-sensory materials" comprehensively (i.e., the contents of memory in non-memory state).[3] The subconscious mind can act independently on human behavior. But when conscious mind is awake, the subconscious mind is always under the custody and guidance of consciousness and acts on the human behavior less than consciousness mind does. Besides, Frankel's research also shows that people's subconscious content is very rich but not limited to "the pursuit of satisfaction, enjoyment, happiness of life instinct".

\section{THE RELATIONSHIP BETWEEN DESIGN CREATION AND SUBCONSCIOUS}

We used to think that creative thinking was the "black box" of thinking. But now, the characteristics of this kind of thinking are made clear. Through collecting, sorting out and contrasting the results of contemporary related research, I found a close 
relationship between design creation and subconscious. It can be envisaged that if some teaching links can be strengthened based on the principle and laws of subliminal activities in the design teaching, we can improve the effect of design teaching to a certain extent.

A few years ago, a young teacher from Ohio state university came to visit our school. In the communication, when asked about how to stimulate students' inspiration, he mentioned something interesting in his reply: "find something helpful through research", "be a careful observer", and "the subconscious method". He also mentioned a funny thing when he was a student: some of his classmates got themselves drunk and designed when they were in a daze.

Similarly, the bizarre images and scenes in the paintings of Dali, a modern surrealist painter, were based on his dreams.

Whether the subconscious mind plays any role in the design activities? What does it mean for creation? After the related theories of the subconscious mind and creative thinking ware looked up and then the behaviors of design creation were compared with the theories, the important connection between the subconscious and the design creation was found:

- The subconscious mind's way of communication is image and symbol, which is concrete.[4] (the conscious mind's way of communication is language, which is abstract.) In creative design activities, image and symbol is the most effective medium through which we think, communicate, imagine and create. So we can speculate that we use subconscious to think, communicate, imagine and create when we are designing creatively.

- The subconscious mind is a mechanism which plays comprehensive role in dealing with the "non-sensory materials" in the brain (i.e., the contents of memory in the non-recalled mode). The subconscious mind is responsible for the acceptance, transmission, storage, integration, and transformation process of information. In an uninhibited state, the subconscious mind automatically refers to the thinking process during which the consciously or unconsciously absorbed intelligence and knowledges are hybridized and distillated. This process is very similar to some process of creative thinking activity. According to Wallace's four-stage theory of creative thinking, creative thinking activities are comprehensive, which need to enroll all kinds of knowledge and thinking activities to find the answer to a question creatively. The process from brewing stage to epiphany has the characteristics of subconscious thinking activity, although both conscious and subconscious mind are relied on to memorize, store, sort and synthesize the collected information in the "brewing stage”.[5]

- The subconscious mind responds more quickly than consciousness (because the subconscious doesn't need to confirm its own judgment, but operates according to its own internal rules), so someone describes the subconscious as the "responsible executive". In addition, it still generates emotions. It is the warehouse of memory and perceives the world through intuition.[6] For example, we need high level skills when we are skating, typing, or playing graceful flowing music and having interesting and humorous conversations with others at the same time. It is the subconscious rather than the conscious mind that helps us master the perfect skills. In the process of design expression, we also need to be adept at expression skills. We need to deliver our design intention with emotion in design drawings to make the design look vivid and pleasant. And we need to associate all our memory fragments to capture inspirations and create novel, nice and appropriate shapes. In the creative and complicated mental process, we need to coordinate or synchronize drawing and thinking. There is no doubt that we can't complete these tasks without the participation of subconscious activities.

The above analysis shows that there exists a close connection between design creation and subconscious activities. Perhaps we need to rethink design discipline construction with subliminal theory in mind in order to make the teaching process more objective and reasonable.

\section{The PROBlems that ARE SUGGESTED TO BE TAKEN SERIOUSLY IN DESIGN TEACHING}

\section{A. Visual Memory and Subconscious Activity}

First, the basis of subconscious activity is memory.[7] According to the subconscious theory, the subconscious way of communication is image and symbol. And the deeply understood information can be invoked in subconscious activities only when it becomes long-term memory. So, the needed information had better be input early enough before the design task begins to allow the reserved information deposit in long-term memory with plenty of time. What's more, the information input had better be qualified, typical, graphical and symbolized. At the same time, the understanding of it needs to be enhanced and the memory needs to be reinforced. In industrial design, for example, it is not enough just to have a look at excellent products or their pictures --- what else needed to do is to understand the product's function as well as the purpose of its morphology, structure, material and to understand the relationship between them. With this deeply understanding, we may be able to absorb the beneficial parts and use them in the creatively subliminal activities in the future.

Therefore, besides the theory and typical case teaching, the relevant information platform and input channel had better be set up for the students. For example, it is suggested to add some teaching activities that involves appreciation of design works and the training of drawing down a product without watching it in basic design course. It may also be useful to organize student to reproduce some excellent products in models so as to strengthen the understanding and memory of the form, material, structure and material of the works. These memories will form excitations in the brain which will affect the future design outputs. In addition to the information input in classroom, the information input outside the classroom is also very important. 
Designers need to be exposed to an environment where the students can watch some excellent designs quietly. This kind of environment can be created as galleries where the students pass by or hang around every day. Students can get something helpful while watching them over and over again. In addition, it is suggested that teachers build image databases required by their curriculum on the Internet. It is a good exhibition environment for students where they can learn a lot. It is believed that, as time goes on, we can all see the results of being influenced by what one constantly sees and hears in a quiet way.

\section{B. Subconscious Activity and The Training of Design Thinking}

The subconscious activity is the key point to creativity. Whether or not it invokes individual knowledge, experience and memory successfully or deals with the reserved information appropriately, flexibly and effectively enough in creative design activities depends on the efficiency of the information deployment mechanism in the human brain.

However, we don't understand the brain's subconscious activity and its basic information deployment mechanism at the moment. Many of the creative discoveries and inventions of the past have shown that subconscious activity in the brain is hard to detect. We are often surprised by the results of our creation, but are so puzzled about its process. for example, Faya Causey, the director of the ministry of education of the National Gallery of Art, found after her careful studying that the Chinese garden of Suzhou is the original shape of the shared space in the National Gallery of, which was designed by Ieoh Ming Pei who had grown up in a lion's forest but had never been aware of the connection between the two things. This example illustrates again the secrecy of the information deployment mechanism of the subconscious mind and reveals some clues to the relationship between the things in Pei's subconscious mind and his design objects. The connection of the two things was so secret that it was not even perceived by Pei himself. So this kind of connection exists only in the subconscious mind of a designer. That is to say, the thinking activity which connects two things in the subconscious is also secret. The brain is actually trying to match the design object with the other, and the process is not perceived by the designer.

The subconscious activity associated with creative activity is like a black box for designers. More confusion ensues when we recognize some clues about it. How are two irrelevant things linked together? How did the brain find such an appropriate connection? What has the designer felt in these two things and has gotten from them? Were they conscious of their feelings then?

Han Yuxuan has described the creative subliminal activity as complex, rich, comprehensive and profound in his "unspeakable, unutterable subconscious aesthetic feeling". Each designer who has experienced a successful design must have experienced an active period of subconscious activity in the aesthetic or creative process. So they would agree with the description of psychological feelings and mental state in Han Yuxuan's passage, also would they agree with what he mentioned in his article such as the collision of diversified information as well as perception, imagination, emotion, thinking and other mental functions.[8] These subjective feelings are an objective existence, indicating that creative activities of art and design have their own characteristics, which are creative activities of thinking accompanied by aesthetic and emotion.

Therefore, the artistic, intuitive and imaginative handpainting must be an important part of the creative activities of design. Students should be made to stick to it throughout design teaching activities even when they are in the process of critical thinking. At the same time, the corresponding visual perceptional material with aesthetic and emotional function should be presented in the teaching environment all the time. Students need to open up various channels of thinking gradually by sticking to hand-drawn design ideas and by the presenting expressive and imaginative materials. They need to establish such good habits of design expression like this. It is believed that the designers will have more good information allocation mechanism and stronger ability to invoke personal reserved knowledge, experience, information and memory when they have good habits of design thinking and expression. Then, it is possible for them to go into the subliminal activity state more smoothly and quickly and to carry out creative design activities more effectively.

\section{Subconscious Activity and Design Teaching Environment}

The limbic system in the middle brain is responsible for our emotional feelings, which are controlled by the subconscious mind and react upon the subconscious mind.

Although we've all experienced the effects of emotion on thinking and concentration, the state of the art design can't be always consciously realized by all the designers, nor can it be always understood by the manager of design education. Therefore, the design teaching environment would better to be designed by designers who know the designing state. John Eaton, an early teacher of Bauhaus, asked students to do some relaxing exercises before class such as body stretching, breath control, meditation to help release the creative potential that is asleep within.[9] These kind of teaching activities are strange in the eyes of others at that time. It is known that Eaton was influenced by eastern philosophies and introduced these thoughts to teaching activities. But his teaching effect was not obvious, and his unique practice did not get a positive response because of the lack of clear and effective training methods. In fact, the state of "wandering freely" and "spiritual fasts" of "deserting distracting thoughts" mentioned in Zhuangzi’s 《A Leisurely Tour》 and the "wonderful state of attainment" of "the well-connected ability to center the mind in a particular mode of perception" and of the ability to "understand the truth" and "be at ease just as playing games" in Buddhism are really what is needed in art design activities according to the description of the creative composing state of them. [10]

Researches now have found that subconscious and willpower is a pair of contradictions. As conscious activity increases, subconscious activity becomes weaker. The concept of "integration of nature and human" and the thought of "concentrating the attention on the interior nature of the essence of things" promoted by Laozi and Zhuangzi and "heart 
of no delusion" advocated in Buddhism leads people to understand the outside world objectively and profoundly in a natural state of inaction, which is beneficial to subconscious activities. So, we might as well design teaching environment and teaching activities basing on the thoughts in eastern philosophies and the characteristics of subconscious mental life to activate subconscious mind.

\section{CONCLUSION}

Subconscious activities play a key role in creative design activities. We need to give full attention to the research findings of the subconscious mind, and keep them in mind when we consider the curriculum construction of art design. According to the subliminal theories, information input, thinking training and teaching environment are the important points and the following had better be paid attention to:

- Research on the form of information and the way we input information to students, which can affect the efficiency of visual memory and the absorption of information.

- Research on the way of thinking training and the role of hand-drawing and graphic materials in every process of design teaching, especially in training of design thinking.

- Research on the environment that is helpful to improve the efficiency of creative design activities according to the characteristics of subconscious mental life.
The above is mainly theoretical research, and relevant empirical research and quantitative research are needed to demonstrate the correctness of this viewpoint.

\section{REFERENCES}

[1] Encyclopediacard.Subconscious[DB]http://baike.baidu.com/view/19944. htm (In Chinese)

[2] Encyclopediacard.Subconscious[DB]http://baike.baidu.com/view/19944. htm (In Chinese)

[3] G. Frankel. "The exploration of the unconscious mind" (psychoanalytic classic series, frankel psychoanalytic translation) [M]. International cultural publishing company. 2006. (In Chinese)

[4] Encyclopediacard.Subconscious[DB]http://baike.baidu.com/view/19944. htm J. (In Chinese)

[5] encyclopedia card. Creative thinking in the form of [DB]. http://baike.baidu.com/view/658218.html. (In Chinese)

[6] Encyclopediacard.Subconscious[DB]http://baike.baidu.com/view/19944. htm (In Chinese)

[7] Encyclopediacard.Subconscious[DB]http://baike.baidu.com/view/19944. htm (In Chinese)

[8] han yuxuan. "The unconscious aesthetic feelings of the unutterable" Journal of changchun university [J].2014, 24(05): 693-696 (In Chinese)

[9] encyclopediacard.John.Eaton[DB].https://baike.so.com/doc/845023893545.html. (In Chinese)

[10] zhou wenjie, zhou honglu. "Carefree tour: the spirit lifestyle of artists". Journal of dalian university of technology (social science edition) $[\mathrm{J}]$. 2011, 32 (03) : 123-126. (In Chinese)

[11] (South Africa) Ed huzi, (British) jacobs, jia xiaoming. Consciousness and subconscious [M]. Beijing: Peking University medical press, 2008. (In Chinese)

[12] Tong baohua, "Creative Thinking Is a Comprehensive Application of Many Ways of Thinking”. Journal of Zhaoqing University [J]. 2000,03. (In Chinese) 